\title{
Perspectivas Críticas acerca da Relação entre Saúde e Desenvolvimento com Foco nos Países Bric
}

\section{Critical Perspectives Concerning the Relationship between Health and Development Focusing on Bric Countries}

Resumo: A bem conhecida interpretação do desenvolvimento como crescimento econômico e industrialização é analisada em suas origens em programas e políticas internacionais após a guerra de 1940 e correlacionada com a doutrina da Cepal acerca do círculo vicioso entre doença e pobreza. É evidenciado que a evolução posterior das políticas internacionais de saúde veio a enfatizar os problemas que afetam o conjunto da população, independentemente de seu nível de renda. Dois enfoques contemporâneos da questão são discutidos: a saúde como capacidade humana, de Amartya Sen, e a inovação tecnológica em saúde, como uma proposta de inspiração schumpeteriana. Os pressupostos desses dois enfoques são comentados vis-à-vis os dados contextuais dos países Bric, de modo a avaliar seus problemas de saúde e possibilidades de desenvolvimento.

Palavras-chave: Saúde e desenvolvimento. Economia da saúde. Países Bric.

Abstract: The well-known interpretation of development as an equivalent of economic growth and industrialization is examined in its roots in American international cooperation in the post-war era and correlated with the doctrine of Eclac about the vicious circle between poverty and disease. It is shown that later targets of international health policies came to highlight problems that affect the whole population, regardless of their level of income. Two contemporary approaches to this question are discussed: Amartya Sen's notion of health as a human capacity, and innovation in health technologies as a Schumpeterian proposal. The theoretical assumptions of these two approaches are discussed vis-à-vis contextual data of Bric countries, so as to evaluate their health problems and development possibilities.

Keywords: Health and development. Health economics. Bric countries.

JEL Classification: I15.

* Médico. Doutor em Saúde Coletiva e técnico de planejamento e pesquisa do Ipea (Diretoria de Estudos e Políticas de Estado, Instituições e Democracia - Diest). E-mail: roberto.nogueira@ipea. gov.br 


\section{Introdução}

Na segunda metade do século $\mathrm{XX}$, a discussão da relação entre saúde e desenvolvimento por parte de sanitaristas e de economistas foi obscurecida como resultado de uma compreensão limitada de ambos os termos dessa relação. Em primeiro lugar, devido ao pressuposto de que o desenvolvimento viria para melhorar as condições de saúde da população pobre. Em segundo lugar, devido à identificação de desenvolvimento com o crescimento econômico e, especialmente, com o processo de industrialização.

A noção de desenvolvimento como crescimento econômico e industrialização foi formada gradualmente no período que se seguiu à Segunda Guerra Mundial em conexão com as políticas de cooperação internacional aplicadas sob a liderança dos Estados Unidos, sendo difundida com base nos bilhões de dólares que ajudaram na recuperação da economia europeia devastada pela guerra. Em outros continentes, essa noção foi apresentada como a solução definitiva para a questão da pobreza, incluindo a eliminação das doenças endêmicas e, neste particular, embora não diretamente sob a influência americana, deve-se destacar o papel da doutrina da Cepal, que considerava a doença como constituinte dos males estruturais da economia periférica latino-americana.

Nas décadas finais do século $\mathrm{XX}$, as políticas conduzidas pela Organização Mundial de Saúde moveram-se no sentido de enfocar não apenas as doenças da população pobre, mas também os chamados riscos globais, que expressamente não dependem do nível de renda dos grupos sociais. Por outro lado, começa-se a indagar acerca da questão sobre como as diversas dimensões da saúde podem contribuir para o desenvolvimento, através de duas linhas que serão destacadas neste artigo: a) o enfoque de Amartya Sen, que considera ser a saúde uma decisiva forma de capacidade humana para viabilizar o desenvolvimento; b) o enfoque de inspiração schumpeteriana que busca vincular o campo da saúde ao mercado internacional com base em políticas públicas que incentivem as inovações geradas na fronteira tecnológica.

O enfoque das capacidades humanas afirma que a saúde precisa ser priorizada pelas políticas públicas como questão de justiça e igualmente como um importante fator indutivo do desenvolvimento, mas não numa perspectiva restrita de capital humano. Sen considera que o alvo final do desenvolvimento é propiciar condições econômicas e sociais que garantam a liberdade de cada um escolher aquilo que almeja ser e fazer. Por sua vez, o enfoque mais propriamente econômico da inovação em saúde considera que todo o amplo campo da tecnologia em saúde tem grande relevo no front econômico da propriedade intelectual, podendo assegurar a conquista de importantes posições competitivas no mercado internacional. Os pressupostos desses dois enfoques são sucintamente recapitula- 
dos a seguir e comentados criticamente, tendo em vista as políticas internacionais vigentes em cada contexto e as questões relacionadas às possibilidades e limites do desenvolvimento dos países do grupo Bric.

\section{Desenvolvimento e Saúde de acordo com Políticas Internacionais após a Segunda Guerra Mundial}

A noção de desenvolvimento como crescimento econômico e aumento da produção industrial surge no período de pacificação e cooperação para a recuperação econômica da Europa que se segue ao término da Segunda Guerra Mundial. Está associada aos fins estratégicos do Plano Marshall, o qual, entre 1947 e 1951, canalizou bilhões de dólares com vistas à recuperação da base industrial e agrícola dos países europeus mais afetados pela guerra (ARRIGHI, 2007).

Difunde-se nesse contexto a ideia de que todas as sociedades nacionais podem passar por etapas sucessivas de mudanças econômicas, chegando eventualmente ao ponto de desenvolvimento já alcançado pelos Estados Unidos (WALLERSTEIN, 2004). Essa concepção de desenvolvimento como processo linear e que avança por estágios prestava-se também para despertar esperanças em relação a um futuro melhor entre os países economicamente atrasados da Ásia e da América Latina, vindo a se consolidar posteriormente como doutrina econômica através de Rostow, cuja obra, datada de 1960, denomina-se significativamente de As etapas do crescimento econômico e tem como subtítulo Um manifesto não comunista. ${ }^{1}$

Portanto, o entendimento de desenvolvimento como crescimento da produção econômica e principalmente da indústria está claramente conectado ao esforço americano de reconstrução da Europa no pós-guerra e com as políticas sociais e econômicas divulgadas pelas agências internacionais neste contexto. Desenvolver as economias nacionais era parte da estratégica americana para obviar a opção por regimes de cunho socialista.

A cooperação fornecida através do Plano Marshall favoreceu a geração gradual nos países europeus dos fundamentos políticos e econômicos do Estado de Bem-Estar na Europa, entre 1946 e 1960. A própria saúde seria doravante entendida como um bem-estar. Em 1946, numa assembleia dos ministros da saúde de todo o mundo, em Nova Iorque, a Organização Mundial da Saúde emite a bem conhecida formulação do conceito de saúde, incorporada como artigo de sua Constituição: "um estado de completo de bem-estar físico, psíquico e social". Essa definição oficial, que associa a saúde ao bem-estar social, por certo surgia como algo muito conveniente num período em que era necessário garantir bons

Diversos economistas latino-americanos lançaram críticas às concepções de Rostow sobre desenvolvimento; ver, por exemplo, o que diz Caio Prado Junior (1991) no capítulo inicial de seu livro História e Desenvolvimento. 
resultados por parte das políticas sociais e econômicas, inclusive para contornar a ameaça da instauração de novos regimes socialistas em várias partes do mundo.

É justamente a nação vencedora, e mais que nunca hegemônica do sistema capitalista mundial, os Estados Unidos, que anunciava nesse momento a abertura de um novo horizonte de cooperação internacional, iniciativa que veio a inspirar a criação posterior de uma agência especializada nesta finalidade, a Usaid. Em 1961, muitos dos objetivos e estratégias implícitas do Plano Marshall foram incorporados no programa da Aliança para o Progresso, lançado por John Kennedy especificamente para os países latino-americanos, e que procurava implicitamente induzi-los a uma alternativa de desenvolvimento democrático-capitalista face ao precedente ameaçador criado pela revolução cubana.

A noção de desenvolvimento que se esboça nesse período está nitidamente fundada em pressupostos utilitaristas. O desenvolvimento é eticamente justificável na medida em que, como processo de longo prazo, tende a maximizar o bem-estar na população, ou seja, como resultado de uma somatória de utilidades, aporta bem-estar para o maior número possível de pessoas.

Esse pressuposto utilitarista faz com que o desenvolvimento seja considerado algo bom em si mesmo, um valor a ser perseguido por todas as nações. Portanto, nesta avaliação não entram considerações acerca de equidade e de liberdade, como ocorrerá posteriormente mediante enfoques distintos.

Em 1948, as Nações Unidas criam a Comissão Econômica para a América Latina (Cepal). Segundo a doutrina originária da Cepal, era necessário romper com os círculos viciosos da economia nos países latino-americanos. Os círculos viciosos estavam enraizados nas condições de reduzida produtividade do trabalho e de baixos níveis de poupança e de educação da população, algo que só poderia ser superado mediante um processo de industrialização que garantisse maior autonomia desses países periféricos em relação aos centrais (BIELSCHOWSKY, 2009).

A solução inicialmente arbitrada por Raúl Prebisch e outros economistas da Cepal indicava que a industrialização da economia em substituição às exportações de produtos primários representava o caminho correto para alcançar o desenvolvimento, com melhores condições de vida para todos. Em tese, os círculos viciosos da economia deveriam ser rompidos a partir do momento em que cada país latino-americano deixasse de ser mero exportador de matérias-primas e fosse capaz de ampliar o mercado de trabalho formal mediante um processo de desenvolvimento industrial "endógeno". ${ }^{2}$

\footnotetext{
Nesse contexto de análise, cumpre mencionar a relevância da contribuição do pensamento de Celso Furtado, ex-assessor da Cepal, o qual, em inúmeras formulações, pronunciou-se contra as visões simplistas do desenvolvimento latino-americano, incapazes de dar conta dos problemas crônicos da pobreza e da exclusão social. Em artigo publicado na Revista da Cepal, ele insiste sobre esse ponto da seguinte maneira: "[...] para entender a lógica da civilização industrial, devese ser antes de qualquer coisa encontrar uma justificativa para o processo de aumento do poder aquisitivo da população, ou seja, para a expansão da massa de salários. Esta justificativa necessariamente extrapola o âmbito da análise econômica tradicional, visto que a distribuição de renda
} 
Uma das versões dos círculos viciosos dizia que a pobreza gera doenças, as quais aprofundam a pobreza, e esta, por sua vez, torna ainda mais graves as consequências econômicas e sociais das doenças. Na década de 1950, a doutrina do círculo vicioso da saúde e da pobreza foi explicitamente referida por um expresidente do Banco Interamericano nos seguintes termos: "A saúde de um povo e de sua economia depende uma da outra. Quando as doenças são frequentes, a produtividade diminui e, por isto, os salários, as condições de habitação e o nível de educação são afetados" (HERRERA apud BERLINGUER, 1978, p. 91).

Tal abordagem ${ }^{3}$ considerava as doenças transmissiviveis e endêmicas da população pobre como obstáculos no caminho do desenvolvimento e como perpetuadoras da condição de vulnerabilidade e de exclusão social da população pobre. Algumas dessas doenças, tais como a malária, ainda perduram como graves problemas de saúde pública. Tanto é assim que o controle da malária está incluído como uma das metas a serem alcançadas internacionalmente até 2015 como parte dos Objetivos de Desenvolvimento do Milênio (ODM).

Em conclusão, pode-se dizer que, ao longo das décadas de 1950 e 1960, as teorias e políticas que relacionavam saúde com o desenvolvimento costumavam considerar a pobreza como a causa principal das doenças, deixando de ver que há outros tipos de problemas de saúde que, em contrapartida, acompanham o desenvolvimento.

\section{A Emergência das Políticas de Controle dos Riscos Globais de Saúde}

Na segunda metade do século XX, as doenças transmissíveis diminuíram bastante sua importância na estrutura de mortalidade e de morbidade de muitos dos países latino-americanos. No caso brasileiro, a partir dos anos 1980 e abrangendo os resultados obtidos pelo impulso desenvolvimentista do "milagre brasileiro" da década anterior, constatava-se o aumento da prevalência das doenças crônicas e degenerativas, a par da grande incidência das mortes por acidentes de transporte e homicídio, concentrados justamente nas regiões mais industrializadas do país. No entanto, pelo menos duas tendências positivas se associaram ao processo de desenvolvimento nacional nesse período: a diminuição das taxas de fecundidade e de mortalidade infantil.

Foi na década de 1980 que a experiência brasileira convenceu os sanitaristas de que há certos tipos de problemas de saúde que inevitavelmente acompanham

é determinada por fatores de natureza institucional e política" (FURTADO, 1998).

3 Somente uma investigação histórica mais detalhada poderia estabelecer se tal abordagem foi formulada pelo Banco Interamericano com base nas interpretações cepalinas dos círculos viciosos das economias subdesenvolvidas ou se foi concebida no âmbito da própria Cepal e assumida pelo BID. De qualquer modo, cumpre destacar que, ao longo da década de 1960, essas duas instituições mantiveram laços estreitos de colaboração intelectual, que passavam, em primeira instância, por seus dirigentes, Raúl Prebisch e Felipe Herrera. 
o desenvolvimento e que a saúde deveria ser incorporada na Constituição como um dever do Estado e um direito de todos. Esse entendimento foi estabelecido em franco confronto com as políticas neoliberais de certas agências internacionais que recomendavam a adoção de programas focalizados na atenção à saúde da população pobre.

A situação atual da mortalidade proporcional no Brasil de acordo com os principais grupos de causa é mostrada na Tabela 1, que evidencia a grande importância alcançada pelas doenças não transmissíveis e outros tipos de agravos à saúde.

As doenças transmissíveis mais importantes perfazem atualmente menos de 5\% da mortalidade no país, a despeito do impacto da letalidade por Aids, gradualmente atenuado ao longo das últimas duas décadas por meio de terapias eficazes que garantem de maior sobrevida aos doentes.

Figuram atualmente, como importantes causas de morte, os distúrbios cardiovasculares, os diversos tipos de câncer, as causas externas (homicídios e acidentes de transporte) e as doenças endócrinas, nutricionais e metabólicas. Em relação a muitas dessas doenças, o sobrepeso e a obesidade representam fatores desencadeadores ou agravantes.

A partir da década de 1990, ficou claro que cada vez menos a deficiência nutricional e cada vez mais o excesso alimentar hipercalórico era o responsável por graves problemas de saúde. A obesidade, o diabetes e a hipertensão tornaram-se reconhecidamente problemas sérios de saúde no Brasil e globalmente.

Tabela 1 - Brasil, 2010. Mortalidade proporcional (\%) segundo grupos de causas, CID10

\begin{tabular}{l|c}
\hline \multicolumn{1}{c|}{ Grupo de Causas de Mortalidade - 2010 } & Percentual \\
\hline I. Algumas doenças infecciosas e parasitárias & 4,3 \\
\hline II. Neoplasias (tumores) & 15,7 \\
\hline IV. Doenças endócrinas, nutricionais e metabólicas & 6,2 \\
\hline IX. Doenças do aparelho circulatório & 28,6 \\
\hline X. Doenças do aparelho respiratório & 10,5 \\
\hline XI. Doenças do aparelho digestivo & 5,1 \\
\hline XX. Causas externas de morbidade e mortalidade & 12,5 \\
\hline Demais causas definidas & 17,1 \\
\hline Total & 100,0 \\
\hline
\end{tabular}

Fonte: Datasus (2010).

Nota: Dados preliminares para 2010.

Um relatório recente da Organização Mundial da Saúde (WHO, 2009) afirma que os riscos globais de mortalidade afetam países de todos os níveis de renda e incluem: 
a) hipertensão arterial (13\% das mortes globalmente);

b) o consumo de tabaco (9\%);

c) glicose sanguínea alta (6\%);

d) sedentarismo (6\%);

e) excesso de peso e obesidade (5\%).

Sendo independentes do nível de renda da população e até da capacidade dos investimentos realizados na oferta de serviços de saúde, os riscos globais de saúde não podem ser eliminados tendo por base unicamente os resultados do desenvolvimento dos países. As ações regulatórias dos governos podem ter algum êxito mediante, por exemplo, leis restritivas do tabagismo e da publicidade de cigarros, mas, fundamentalmente, a diminuição da incidência desses riscos requer a mudança de certos comportamentos com base em recursos socialmente disponíveis à população. $\mathrm{O}$ amplo reconhecimento desse fato deu origem às políticas internacionais de promoção da saúde na Conferência de Ottawa de 1986. Na Carta de Ottawa (WHO, 1986) é declarado que a promoção da saúde tem por objetivo “[...] reduzir as diferenças no estado de saúde da população e assegurar oportunidades e recursos igualitários para capacitar todas as pessoas a realizar completamente seu potencial de saúde".

O preceito de "capacitar as pessoas a realizar completamente seu potencial de saúde" suscita seguramente muitas indagações de ordem filosófica e ética, mas sua discussão é complexa e extrapola os objetivos deste artigo. O que convém sublinhar aqui é que, por meio desta declaração, a mais importante entidade de formulação de políticas internacionais de saúde destacava que a "saúde de todos" constitui condição necessária para alcançar o desenvolvimento em sentido amplo (das pessoas, da sociedade e da economia), sendo a saúde entendida como um recurso para a vida social e, ao mesmo tempo, uma capacidade individual que pode e deve ser aprimorada. Mas o que é denominado de equidade sinaliza que essa nova orientação das políticas internacionais de saúde não pode se fundar apenas no incentivo à mudança dos estilos de vida, como se estivessem restritos ao campo da responsabilidade pessoal, mas pressupõe o acesso a ações de políticas públicas, por exemplo, a processos educativos e a meios preventivos adequados.

A declaração de Ottawa é apenas um dos múltiplos testemunhos de que o foco analítico da relação entre desenvolvimento e saúde no século XXI passou a estar dirigido aos problemas de equidade de acesso a recursos sociais de diversos tipos e a objetivos de equidade em saúde que garantam melhoria das condições de vida aos diferentes grupos sociais da população.

\section{Onfoque da Saúde como Capacidade Humana}

A concepção do desenvolvimento como crescimento econômico, medido pelo aumento anual do Produto Interno Bruto, foi combatida por inúmeras cor- 
rentes, com destaque para o pensamento liberal de Amartya Sen. O enfoque de capacidades humanas de Sen é frequentemente apresentado como um antídoto a essa compreensão estreita do desenvolvimento das nações e foi concebido inicialmente como um referencial para as questões de justiça e, especificamente, como um reparo à doutrina de justice as fairness de John Rawls.

A interpretação de Sen assinala que, em geral, a ideia de igualdade é incapaz de fornecer indicações sobre o que deve ser feito para adequadamente responder a situações concretas de injustiça, ou seja, para fornecer subsídios às decisões e políticas de equidade. Como um princípio, Sen $(1982,1992)$ entende que as capacidades humanas estão envolvidas diretamente na resposta à pergunta: igualdade de quê?

Em decisivo ensaio, Sen (1982) toma como caso paradigmático o da pessoa com deficiência física, especificamente, o paraplégico. Falta ao paraplégico a capacidade de saúde de uma pessoa com integridade corporal, que abrange a possibilidade de se mover livremente usando as pernas. Quando se pensa em equidade como objetivo ou valor de uma política pública, convém ter em vista a noção de capacidade na qualidade de uma fonte de onde se origina um conjunto de "funcionamentos" que asseguram a realização daquilo que os indivíduos almejam ser e fazer. As políticas públicas devem buscar sanar ou, pelo menos, minorar as consequências da privação das capacidades humanas, com destaque para saúde, educação e participação na vida política da sociedade. No pensamento de raiz liberal de Sen, as capacidades (capabilities), como viabilizadores das aspirações individuais, são intercambiáveis com a noção de liberdades substanciais (substantive freedoms). Esse posicionamento é estabelecido em claro confronto com os pressupostos utilitaristas de acordo com os quais o fim último do desenvolvimento é a maximização do bem-estar da população.

Em ensaio que trata especificamente da equidade em saúde, Sen (2004, p. 21) salienta o grande alcance da saúde, como uma capacidade humana que, em termos de possibilidade de fazer justiça e de assegurar liberdade, está correlacionada com inúmeras outras dimensões da vida em sociedade; e que, por isto, "[...] a equidade em saúde não pode ser senão uma característica central da justiça em todos os arranjos sociais", não podendo ser reduzida à equidade de acesso a serviços de saúde, por mais importante que esta seja.

A contribuição de Sen para a avaliação da equidade em saúde tem a ver com a equiparação da enfermidade ou das deficiências físicas e mentais à incapacidade de ser livre no cotidiano e no exercício de outras capacidades, implicando, em última instancia, na limitação da cidadania. O que ele denomina de disciplina da equidade em saúde não se limita a considerar apenas as desigualdades concretas das condições de saúde e do acesso a serviços médicos assistenciais.

Assim, Sen entende que a equidade em saúde lida com múltiplas e complexas dimensões que podem ser assim resumidas: 
a) a saúde como capacidade fundamental, que viabiliza o exercício de outras capacidades;

b) a capacidade de uma pessoa alcançar ou manter a saúde;

c) a distribuição social de recursos e o conjunto dos arranjos sociais que ajudam a manter a saúde ou recuperá-la em caso de enfermidade;

d) as condições de inserção social e as características pessoais de cada um.

Sen (2004) sublinha que, de um modo geral, as pessoas tendem a escolher a saúde quando as oportunidades para isso lhes são socialmente oferecidas, embora possa haver também a escolha por hábitos nocivos que atuam como fatores de risco. Ele diz que aquilo que a epidemiologia moderna denomina de comportamento de risco, como o tabagismo, pode resultar de uma falta de liberdade gerada por influências psicológicas que impedem a pessoa de dominar a compulsão ao hábito. O posicionamento ético-filosófico de Sen acerca da relação entre autonomia pessoal e os fatores de riscos de doenças não transmissíveis não são claros o suficiente, sendo esta uma omissão digna de nota, visto que a questão do controle dos comportamentos de risco em saúde tem sido alvo de incessantes polêmicas.

Uma das perguntas relevantes inspiradas pelo pensamento de Sen é a seguinte: que estilo de desenvolvimento favorece a diminuição das desigualdades em saúde e fomenta as capacidades humanas? Sen (2000) critica o fato de que se valoriza no conceito de crescimento econômico apenas a ampliação do volume e do valor das transações econômicas, ignorando que o crescimento da economia deveria abrir uma via para o Estado financiar a seguridade social, a saúde e outras intervenções públicas orientadas pela equidade.

O desenvolvimento não pode ser avaliado com base na ótica estreita das taxas anuais de crescimento do Produto Interno Bruto, mas precisa considerar a amplitude dos serviços oferecidos a toda a população e, sobretudo, a criação de oportunidades sociais mediante serviços como os de educação e de saúde pública. Melhores níveis de saúde, de educação e de liberdades públicas (como a garantia de uma imprensa livre e atuante) podem contribuir tanto para o crescimento econômico quanto para reduções significativas nas taxas de mortalidade. As liberdades básicas são influenciadas, de um lado, pela garantia de direitos individuais, do ambiente de tolerância e da livre troca de bens e serviços, e, de outro, pela manutenção pelo Estado de uma adequada estrutura de atendimento das necessidades de saúde e de educação que são de crucial importância na formação e no uso das capacidades humanas. É bastante conhecida a tese de Sen de que as epidemias de fome jamais ocorreram em nações com regimes democráticos.

De modo renitente, Sen jamais chegou a detalhar uma lista das capacidades humanas básicas, ou seja, algo similar às liberdades básicas de Rawls. Aparentemente seu intento é deixá-las como um conceito amplo e flexível que inspire as 
iniciativas de políticas públicas e das instituições de justiça de cada sociedade; portanto, por fora de definições e normas estritas.

Uma discípula de Sen, coautora de alguns de seus livros, a filósofa Martha Nussbaum (2011, p. 33), pretende ultrapassar este limite e define uma série de capacidades centrais, algumas das quais estão claramente relacionadas com a saúde, a saber:

Vida. Ser capaz de viver a vida até o término de sua duração normal; não morrer prematuramente ou previamente a que sua vida esteja tão reduzida que não valha a pena ser vivida;

- Saúde corporal. Ser capaz de ter uma boa saúde, incluindo a saúde reprodutiva; ser adequadamente nutrido; ter uma habitação adequada.

- Integridade corporal. Ser capaz de se mover livremente de um lugar para outro; estar seguro em relação a assalto violento, incluindo violências sexuais e domésticas; ter a oportunidades de satisfação sexual e de escolha em matéria de reprodução.

Neste campo, as contribuições de Nussbaum estão declaradamente filiadas à linha de defesa dos direitos humanos, com forte influência do pensamento feminista. Nussbaum sublinha que este é um ponto de vista que mantém em comum com o pensamento de Sen, embora, como estratégia política, ela faça uso mais intensivo do ideal dos direitos humanos. Contudo, a ênfase na análise de aspectos do desenvolvimento está ausente nesta autora, sendo, ao contrário, um ponto de realce no pensamento de Sen, o qual pressupõe que deveria existir uma relação direta entre o grau de fomento das capacidades humanas e o desenvolvimento de cada nação.

$\mathrm{Na}$ obra que pode ser considerada a síntese cabal de suas ideias sobre o tema, Desenvolvimento como liberdade, Sen (2000) antevê a necessidade de que as nações alcancem primeiramente certo patamar de investimento em infraestrutura de atenção à saúde antes que possa ocorrer um impulso decisivo no rumo do desenvolvimento. Um dos exemplos que aduz a este respeito tem por base uma comparação entre a China e a Índia. Esses dois países realizaram esforços consideráveis no sentido de abrir um ciclo de desenvolvimento mediante uma economia amplamente internacionalizada e aberta ao mercado externo - a China, após as reformas de 1979, e a Índia, a partir de 1991. Mas o sucesso obtido pela China foi incomparavelmente superior ao da Índia, devido a ter realizado investimentos consideráveis em saúde e educação durante o período maoísta.

Quando a abertura aos mercados mundiais ocorreu em 1979, a China já contava com uma população altamente alfabetizada e com um nível de diferenciação educacional da geração jovem não muito diferente de outros países asiáticos que realizaram a virada para o desenvolvimento, como Coreia do Norte e Formosa. Mas a Índia ainda enfrentava enormes barreiras estruturais para alcançar a univer- 
salização da oferta de serviços básicos de saúde e educação, e tal situação persiste até os dias atuais.

É importante sublinhar, em adendo às observações de Sen, que essas diferenças se relacionam com as possibilidades de modernização efetiva da sociedade e de resultados de equidade obtidos nessas duas nações - algo que não pode ser avaliado somente com base no aumento do PIB da Índia que, em anos recentes, vem apresentando taxas em torno a $8 \%$, aproximadas às da China.

Quanto a esses aspectos é conveniente recorrer ao Índice de Desenvolvimento Humano (IDH) para cotejar a situação socioeconômica dos países Bric. O IDH foi concebido em 1990 pelo PNUD como uma proxy das capacidades humanas. Atualmente, devido a sucessivas mudanças metodológicas, o IDH resulta da média geométrica de três índices:

a) vida longa e saudável (com base na expectativa de vida ao nascer);

b) conhecimento (por meio de dois indicadores: escolaridade média e expectativa de escolaridade);

c) índice de expectativa de vida decente (de acordo com a Renda Nacional Bruta per capita, pareada em valores de poder de compra comparáveis internacionalmente, PP\$). ${ }^{4}$

O IDH tem muitas limitações como avaliador das capacidades humanas. Um deles é o fato de que se apoia na Renda Nacional Bruta (RNB), e depende de circunstâncias bastante conjunturais da economia. Mesmo quando ajustado pelo poder de compra de cada país, a RNB per capita constitui apenas um indicador atrelado ao ritmo de crescimento econômico e está longe de ser um bom índice da potencialidade de bem-estar da população. Contudo, como acentua Sen, o crescimento da economia fornece a base necessária para alcançar maior equidade nas políticas públicas centradas nas capacidades humanas.

Tabela 2 - Países Bric. Índices componentes do IDH

\begin{tabular}{ccccc}
\hline Índice & Brasil & Rússia & Índia & China \\
\hline IDH 2010* & 0,718 & 0,755 & 0,547 & 0,687 \\
\hline Saúde & 0,844 & 0,770 & 0,717 & 0,843 \\
\hline Educação & 0,663 & 0,784 & 0,450 & 0,623 \\
\hline $\begin{array}{c}\text { Renda - Renda Nacional } \\
\text { Bruta p/ cap. }\end{array}$ & 0,662 & 0,713 & 0,508 & 0,618 \\
\hline Posição do país & 84 & 66 & 134 & 101 \\
\hline
\end{tabular}

Fonte: PNUD, Informe IDH (2012).

Nota: * obtido pela média geométrica dos índices de saúde, educação e renda.

Os detalhes técnicos sobre as variáveis de composição e de ponderação dos três indicadores do IDH, em sua última revisão, podem ser lidos nas notas que acompanham a edição de 2011. Disponível em: <http://hdr.undp.org/en/media/HDR_2011_EN_TechNotes.pdf > . Acesso em: 2 maio 2012. 
Na Tabela 2, o IDH dos países Bric é desdobrado em seus índices constituintes para que possa fornecer pistas acerca de onde se encontram os problemas sociais de cada país. A Federação Russa desponta com o melhor IDH para 2011, embora nenhum dos quatro países tenha posição de destaque no ranking mundial. A Rússia apresenta os melhores índices tanto na educação quanto na renda per capita, embora em termos de condições de saúde esteja menos bem colocada do que o Brasil e a China. O Brasil tem uma posição muito próxima da China em saúde e educação, mas com uma renda per capita mais elevada. Por sua vez, a Índia ocupa a última colocação em todos os três componentes do IDH.

Como será visto adiante, mediante outros indicadores, a posição de destaque da Rússia no IDH em relação aos demais países Bric é beneficiária dos investimentos econômicos e sociais realizados em educação durante o período soviético, enquanto seu maior problema de saúde encontra-se menos na oferta de serviços públicos e mais nas causas externas de mortalidade devido a generalizados comportamentos de violência.

\section{Indicadores de Desenvolvimento e de Condições de Saúde nos Países Bric}

Em artigo recente divulgado na Internet, Dixe e Sen (2011) fazem a análise comparativa da Índia com a China e outros países asiáticos, tecendo múltiplas críticas à falta de resultados do crescimento econômico da Índia para a saúde de sua população, acentuando que o crescimento econômico é apenas um meio e não um fim em si mesmo. Entretanto, os autores justificam a necessidade de crescimento acelerado no caso da Índia porque sua renda média é tão baixa que não pode sustentar qualquer coisa similar a um padrão de vida razoável, mesmo com ampla redistribuição de renda. Isto acontece porque, ainda nos dias atuais, após 20 anos de rápido crescimento, a Índia é um dos países mais pobres do mundo.

Dreze e Sen mencionam em seguida que uma situação similar à da Índia, de acelerado crescimento econômico com ausência de bons resultados no campo social, ocorreu no Brasil durante a ditadura militar. Eles exaltam a consagração da saúde como direito de todos na Constituição de 1988 e a política de distribuição direta de renda à população pobre através do programa Bolsa Família.

Essas referências às condições sócio-econômicas dos três países mencionados, Índia, China e Brasil, tornam oportuno agregar aqui uma comparação sumária de condições de saúde entre os países que constituem o grupo Bric.

As tabelas seguintes trazem um conjunto de indicadores que comprovam que, de fato, a Índia ainda se encontra bastante atrasada em termos de condições de saúde e de investimentos públicos na área quando comparada não só com a China, como também com o Brasil e a Federação Russa. 
Tabela 3 - Índia, China e Brasil. Indicadores de condições de saúde e de investimento público em saúde, 2009

\begin{tabular}{ccccc}
\hline Indicador & Brasil & Rússia & Índia & China \\
\hline Fecundidade* & 1,8 & 1,4 & 2,7 & 1,8 \\
\hline Expectativa de vida** $^{*}$ & 73 & 68 & 65 & 74 \\
\hline Mortalidade infantil*** $^{* * *}$ & 17 & 11 & 50 & 17 \\
\hline Mortalidade neonatal*** $^{*}$ & 12 & 6 & 34 & 11 \\
\hline $\begin{array}{c}\text { Gasto público per capita } \\
\text { em saúde**** }\end{array}$ & 385 & 633 & 40 & 126 \\
\hline
\end{tabular}

Fonte: World Health Statistics (2011).

Notas: *Número de filhos por mulher;

$* *$ ao nascer, em anos, ambos os sexos;

*** taxa padronizada por idade para ambos os sexos por mil nascidos vivos;

**** equivalente de poder de compra pareado internacionalmente (PPP int. \$); dados para 2008.

A Tabela 3 mostra que a Índia, com uma taxa de fecundidade de 2,7 filhos por mulher, é o único país do grupo Bric acima do limiar de reprodução estável da população (ou seja, 2,1), o que implica que sua população continuará a crescer na década atual.

Segundo estimativas de agências da ONU, a população da Índia deverá ultrapassar a da China em 2035. Ademais, a Índia exibe uma mortalidade infantil de 50 e uma mortalidade neonatal de 34 por mil nascidos vivos, valores extremamente elevados em relação a inúmeros outros países do Terceiro Mundo, exceto os da África. O gasto público per capita em saúde da Índia corresponde a um terço do gasto chinês e a cerca de um décimo do gasto brasileiro.

Os seguintes pontos de análise podem ser destacados para efeito de comparação dos quatro países Bric:

a) os indicadores de condições de saúde mostram-se relativamente favoráveis ao Brasil em comparação com a Índia e parcialmente em relação com a Rússia, e numa posição pareada com a da China, embora a China tenha uma despesa com saúde proporcionalmente bem menor;

b) as despesas públicas per capita com saúde do Brasil são inferiores apenas às da Rússia (de acordo com o indicador pareado de poder de compra);

c) a Rússia tem indicadores de saúde aparentemente discrepantes. Devido ao deterioro das condições de vida peculiares ao período pós-soviético, houve um retrocesso na expectativa de vida da população russa, o que implicou uma queda da expectativa de vida de cerca de 20 anos e só recentemente alcançou índice similar ao final da década de 1980. Contudo, a Rússia tem como vantagem o fato de dispor de uma rede de serviços de saúde com boa cobertura pública, que vem do período 
soviético, o que garante, por exemplo, que o país exiba taxas relativamente baixas de mortalidade neonatal e infantil.

Não deve causar surpresa o achado de que as condições de saúde da população brasileira são muito assemelhadas às da população chinesa, embora o Brasil tenha nessa área uma despesa pública bem maior. É bem sabido que os níveis de saúde dependem de muitas outras condições sociais e de vida, além do acesso a serviços médicos/sanitários aos quais corresponde essa despesa. Pode-se aqui presumir que a população chinesa se beneficia de uma maior equidade em relação a outros serviços públicos (como educação) e de maiores oportunidades de trabalho, renda e qualidade de moradia e de condições de saneamento ambiental, bem como, em algumas regiões, de certos estilos de vida tradicionais que favorecem a saúde e a longevidade.

Por sua vez, a Tabela 4 evidencia o peso considerável que as doenças transmissíveis ocupam na estrutura de mortalidade da Índia em comparação com os outros três países em referência. Na Índia, a taxa de mortalidade por doenças transmissíveis corresponde a 53\% da taxa por doenças não transmissíveis, enquanto na China representa apenas 9,6\% e no Brasil 18,2\%. A persistência de uma alta incidência de mortalidade por doenças transmissíveis na Índia evidencia que este país ainda se encontra num estágio incipiente da transição epidemiológica, ao contrário dos outros três.

Tabela 4 - Países BRIC. Taxas de mortalidade por grupos de causas específicas, 2009

\begin{tabular}{ccccc}
\hline Causa $^{*}$ & Brasil & Rússia & Índia & China \\
\hline 1. Doenças transmissiveis & 97 & 71 & 363 & 58 \\
\hline $\begin{array}{c}\text { 2. Doenças não trans- } \\
\text { missíveis }\end{array}$ & 534 & 797 & 685 & 604 \\
\hline 3. Causas externas & 76 & 159 & 99 & 70 \\
\hline \% 1 em relação a 2 & 18,2 & 8,9 & 53,0 & 9,6 \\
\hline
\end{tabular}

Fonte: World Health Statistics (2011).

Nota: * Taxa padronizada por idade, por 100.000 habitantes.

Chama a atenção, por outro lado, que todos os países Bric apresentam taxas muito elevadas de mortalidade por causas externas. Mas a Rússia se destaca com uma taxa extraordinariamente alta, de 159 por 100 mil habitantes, que ser relaciona, sobretudo, à grande incidência de homicídios naquele país, que é uma das mais altas do mundo.

Após revisão de literatura sobre saúde pública na Rússia, Pridemore (1921, 1922) conclui que a elevação dessa taxa está relacionada com aumentos acentuados no consumo de álcool e com a violência letal que o acompanha. Citando Durkheim, ele afirma que o aumento das causas externas de mortalidade nessa 
república, após o período soviético, está relacionado com a situação de anomia social vivida nas últimas duas décadas por essa nação.

Com efeito, os dados sobre três tipos de fatores de riscos (Tabela 5) mostram que a Rússia apresenta o mais alto índice de consumo de bebidas alcoólicas, com o Brasil em segundo lugar. Em contraposição, a magnitude do consumo de álcool na Índia é desprezível. A obesidade é bem mais elevada no Brasil e na Rússia do que na China e na Índia.

Finalmente, como mais um fator de risco, o hábito tabagista está presente entre mais da metade da população masculina na Rússia e na China; e no Brasil estende-se apenas a um quinto do sexo masculino, embora o diferencial entre os dois sexos seja relativamente pequeno.

Tabela 5 - Países Bric. Indicadores de fatores de risco à saúde, 2006 a 2008

\begin{tabular}{ccccc}
\hline Indicador* & Brasil & Rússia & Índia & China \\
\hline Adultos obesos* & 16,5 e 22,1 & 18,4 e 19,8 & 1,3 e 2,5 & 4,6 e 6,5 \\
\hline Consumo de álcool ** & 6,2 & 11,0 & 0,6 & 4,4 \\
\hline Tabagismo (\%)** & 19,4 e 12,0 & 70,1 e 27,7 & 33,2 e 3,8 & 59,5 e 3,7 \\
\hline
\end{tabular}

Fonte: World Health Statistics (2011).

Notas: * Percentual, respectivamente, de homens e mulheres obesas, entre adultos de $\geq 20$ anos; ** consumo equivalente a litros de álcool puro por pessoa por ano entre adultos de $\geq 15$ anos;

*** percentual, respectivamente, de homens e mulheres, que fazem uso de tabaco de qualquer tipo, entre adultos de $\geq 15$ anos.

A interpretação desses indicadores referentes às duas últimas décadas vem a ratificar aquilo que Sen afirma acerca da superioridade obtida historicamente pela China em relação à Índia em termos de aprimoramento das capacidades humanas. A Federação Russa, por sua vez, a despeito de contar com um eficiente sistema público de saúde, enfrenta o desafio de recuperar-se em relação às condições sociais de anomia, as quais têm fortemente favorecido as causas externas de mortalidade em associação com o abuso do consumo de álcool.

Quanto ao Brasil, o aspecto mais preocupante é o crescente aumento da prevalência do sobrepeso e obesidade em ambos os sexos, condição que se relaciona com maior risco de enfermidades cardiovasculares e o diabetes. Finalmente, o cotejamento mais amplo leva a concluir que, quanto às condições de saúde de sua população, o Brasil não se defronta atualmente com qualquer desvantagem comparativa dentro do grupo Bric e se encontra claramente pareado com a China.

\section{A Saúde e a Nova Economia da Inovação}

Na década de 1990, os fatos da integração comercial em escala global e, adicionalmente, o fenômeno da ascensão econômica da China e de outros países 
da Ásia criaram sérios interrogantes acerca da viabilidade da industrialização dos países periféricos nos moldes originalmente concebidos pelo pensamento estruturalista da Cepal. A busca de alternativas levou esta entidade a considerar novos caminhos que passam pela conquista ou consolidação de certas vantagens competitivas por parte dos países latino-americanos. Tem início então uma linha doutrinária, denominada de neoestruturalista, a qual, no âmbito de uma diretiva geral de "transformação produtiva com equidade", caracteriza-se por enfatizar:

[...] o caráter sistêmico da competitividade, priorizando a criação de infraestrutura física, a formação de recursos humanos e as políticas de inovação e avanço tecnológico para alcançar um crescimento mais elevado e sustentado, bem como uma inserção internacional exitosa. (BIELSCHOWSKY, 2009, p. 179).

Segundo Pérez (2010), a América Latina deveria buscar estratégias alternativas, tirando partido da abundância dos recursos naturais existentes nessa região, o que implicaria impulsionar, de um lado, uma vertente de desenvolvimento voltada para a promoção da produção de alto valor agregado, relacionada com inovações ou aperfeiçoamentos tecnológicos, e, de outro, uma vertente de processos produtivos fundada em recursos naturais. Pérez (2010, p. 124) ratifica tal ideia partindo do pressuposto de que "[...] é muito importante identificar áreas com potencial tecnológico onde a América Latina tenha vantagem comparativa sobre a Ásia”.

A proposta de maximizar o benefício dos recursos naturais dos países da América Latina deve ser amplamente debatida tendo em vista as possibilidades, sempre muito prováveis de conflito com as políticas e os movimentos de proteção ambiental. Não costuma ser devidamente considerado qual é o custo ambiental acarretado por esse modelo de desenvolvimento, na medida em que tal proposta implica grande reforço ao agronegócio e à exploração de commodities metálicas e energéticas voltada para a exportação (PORTO; MILANEZ, 2009).

Essas duas referências, recuperadas aqui muito brevemente e sem aprofundamento analítico, servem para indicar a proeminência da linha de pensamento desenvolvimentista fundada na perspectiva da inovação tecnológica. Em termos um pouco simplista, essa ênfase tem sido referida sob o lema "ultrapassar as políticas keynesianas", como o fazem Aghion e Roulet (2011), autores que consideram que se de um lado a teoria da geração de demandas efetivas foi fundamental para ajudar a criar as bases do Estado de Bem-Estar no pós-guerra, por outro, na conjuntura criada após os anos 1980, devido à forte competição internacional, a economia dos países mais desenvolvidos da Europa não pode mais estar sustentada nas despesas públicas, de acordo com um modelo de economia industrial e de serviços mais ou menos fechado em si mesmo. Numa economia voltada para a inovação, "[...] as novas empresas e os novos empregos são criados permanentemente, 
enquanto outros são destruídos, daí a importância de o Estado não tanto controlar diretamente as empresas, mas as regular" (AGHION; ROULET, 2011, p. 8-9).

Por meio de linha similar de interpretação, Jessop (2002) afirma que o Estado keynesiano dos grandes sistemas de bem-estar nascidos no pós-guerra na Europa está sendo substituído pelo que ele denomina de Estado Competitivo Schumpeteriano, que se volta para a gestão da crise criada pelo acirramento da competição internacional. O que essa forma de Estado em última instância busca é rendas extraordinárias que decorrem do monopólio das invenções e do sistema de propriedade intelectual, na medida em que "[...] depende de modo acentuado da busca por rendas tecnológicas baseadas em inovação contínua, em monopólios de fato no campo das tecnologias avançadas, ou seja, dos direitos de propriedade intelectual" (JESSOP, 2000, p. 100).

Quanto a este aspecto do novo desenvolvimentismo, a posição débil do Brasil e a extraordinária vantagem da China no grupo podem ser aquilatadas pelos indicadores da Tabela 6. Com efeito, em 2010, 84,2\% de todas as patentes em vigor obtidas pelos países Bric pertenciam à China, ao aplicar 8,9\% das despesas mundiais em CTEI, mais do que a soma dos demais países do grupo.

Tabela 6 - Países BRIC. Indicadores de ciência, tecnologia e inovação (CTEI)

\begin{tabular}{cccccc}
\hline Indicador & Brasil & Rússia & Índia & China & Bric \\
\hline Pesquisadores por 100 mil habitantes* & 657 & 3.305 & 137 & 1.071 & 5.170 \\
\hline $\begin{array}{c}\text { Participação (\%) na despesa mundial com } \\
\text { CTEI* }\end{array}$ & 1,8 & 2,0 & 2,2 & 8,9 & 14,9 \\
\hline Número de patentes requeridas** & 22.686 & 34.287 & 42.500 & 391.177 & 490.650 \\
\hline \% de patentes requeridas no grupo Bric & 4,6 & 7,0 & 8,7 & 79,7 & 100,0 \\
\hline Número de patentes concedidas** & 3.251 & 30.322 & 6.168 & 135.110 & 174.851 \\
\hline \% de patentes concedidas no grupo Bric & 1,9 & 17,3 & 3,5 & 77,3 & 100,0 \\
\hline Número de patentes em vigor & 40.022 & 181.904 & 37.334 & 564.760 & 670.886 \\
\hline \% de patentes em vigor no grupo Bric & 6,0 & 27,1 & 5,6 & 84,2 & 100,0 \\
\hline
\end{tabular}

Fonte:Unesco (2010) e WIPO Report (2011).

Notas: *Em 2007 ou ano mais recente (Unesco); ** em 2010 (WIPO Report 2011).

De sua parte, a Rússia detém o maior número relativo de pesquisadores e está em segundo lugar quanto ao número de patentes concedidas. Esses indicadores mostram cabalmente a situação de inferioridade do Brasil em termos de investimentos e resultados comparativos nesse campo. O Brasil tem um grande atraso histórico em relação aos demais países Bric não só no campo da educação em geral como também, em particular, em CTË, e como ressalta Arbix (2010, p. 32), foi somente a partir de 2003 que a ação estatal "[...] abriu um capítulo novo na construção de uma estratégia baseada-na-inovação”. 
É bem sabida a importância estratégica ocupada dentro da "economia do conhecimento" pelas tecnologias em saúde tais como os meios computadorizados de diagnóstico, a biotecnologia, a robótica, a inovação farmacêutica, etc., o que faz com que o complexo de produção industrial e de pesquisa em saúde seja um dos mais importantes geradores de direitos de propriedade intelectual (VIANA; ELIAS, 2007).

No Brasil, alguns economistas da saúde vêm se pondo em consonância com essa linha de inspiração schumpeteriana ${ }^{5}$ e acentuam as possibilidades abertas pela demanda internacional em relação aos produtos e equipamentos de saúde, tanto para fins de diagnóstico como de terapia, envolvendo a descoberta de novos fármacos, a robótica, os equipamentos informatizados e a nanotecnologia. Frequentemente essas inovações são apresentadas como sendo não só de interesse para a profissão médica como também para as pessoas enfermas e para a Saúde Pública, sobretudo quando envolvem métodos de detecção precoce de doenças tais como o câncer.

Numa perspectiva de equidade, contudo, a ênfase na criação de laços entre o campo da atenção à saúde e a indústria de alta tecnologia suscita muitas preocupações (GADELHA; COSTA, 2006). Os custos das patentes e das tecnologias de ponta de diagnóstico e terapia incidem de modo não equitativo sobre as despesas das famílias, de modo a desfavorecer a assistência aos mais pobres, criando novas formas de desigualdade no acesso a bens e serviços de saúde.

Stiglitz (1996, p. 196) salienta esta particularidade negativa dos sistemas de patentes com muita contundência em relação aos medicamentos, quando adverte que "[...] regimes de propriedade intelectual mal projetados não somente reduzem o acesso a medicamentos como também levam a uma economia menos eficiente e podem até diminuir o ritmo da inovação".

O setor saúde certamente tem um papel muito importante a cumprir dentro da estratégia de desenvolvimento fundada nos investimentos em inovação. Contudo, conforme Gadelha (2006, p. 15), esta via se impõe com o fito de que o Brasil venha a superar a dependência tecnológica e, por outro lado, cabe ao Estado executar políticas que ressalvem os interesses da equidade em Saúde Pública, "[...] na direção do dinamismo econômico e da superação do atraso em áreas críticas para a atenuação da desigualdade e da exclusão social". Este é um argumento forte e relevante para que não se perca de vista a complexidade da interação entre saúde e desenvolvimento, tomando em conta as desigualdades sociais de nosso país.

Uma exposição sistemática da visão neo-schumpeteriana que associa o complexo médico-industrial e da inovação em saúde encontra-se em Gadelha, Quantal e Fialho (2003). 


\section{Considerações Finais}

Os enfoques das capacidades humanas e da inovação devem ser analisados em suas diferenças essenciais enquanto fundamentadores de propostas de políticas públicas para o desenvolvimento. A teoria de Amartya Sen foi elaborada como culminância de uma longa investigação sobre equidade e justiça distributiva, mantendo, por outro lado, uma íntima conexão com os objetivos do movimento internacional dos direitos humanos. A relação entre saúde e desenvolvimento é definida pela convergência destas duas dimensões em direção à liberdade. Tanto a proteção social à saúde quanto o desenvolvimento justificam-se pelo fomento da liberdade, visto que a saúde é o fundamento das potencialidades pertinentes às demais capacidades humanas. Mas é preciso sempre ressaltar que Sen pressupõe que o alcance de melhores condições de saúde dar-se-á mediante conquistas sociais complementares, incluindo a eliminação da pobreza extrema e a distribuição de renda ao longo do processo de crescimento econômico.

A maior debilidade do enfoque de Sen sobre a saúde como capacidade humana talvez esteja manifesta na falta de uma interpretação consistente da questão dos fatores de risco, o que transparece em sua análise de que o tabagista é vítima de suas dificuldades psicológicas de largar o hábito. Aqui, paradoxalmente, Sen não parece ser consentâneo com o princípio que advoga de que toda capacidade humana consiste numa liberdade de escolha e de realização de funcionamentos. É possível que tal debilidade resulte do fato de que o enfoque das capacidades humanas foi inicialmente concebido para dar conta das condições de vida das populações pobres e da causalidade peculiar às doenças transmissíveis e nutricionais em países como a Índia, que ainda não completaram sua transição epidemiológica.

A identificação dessa lacuna no pensamento de Sen suscita a necessidade de contar com uma interpretação que não venha em reforço às políticas autoritárias de controle dos fatores de risco em saúde. O que se espera, ao contrário, é que a abordagem da promoção da saúde possa sempre levar em conta o sentido da liberdade que está implícito no entendimento da saúde como capacidade humana.

Por sua vez, o enfoque de inovação precisa ser criticado por consistir essencialmente numa busca de solução diante dos impasses e problemas meramente econômicos gerados no ambiente altamente competitivo da globalização. Esse enfoque tem a economia como objeto primordial, mais precisamente a economia do conhecimento, na medida em que esta possa criar possibilidades de ganhos de monopólio mediante o respeito à propriedade intelectual. Porém, em meio às muitas barreiras injustas criadas pelo sistema internacional de patente, os objetivos da equidade não podem deixar de ser invocados nos debates políticos acerca dessa questão. Os episódios recentes dos conflitos internacionais em torno das patentes de medicamentos para HIV/Aids atestam bem a procedência dessa afirmação. 
O que há de comum entre os dois enfoques referidos neste artigo resulta da possibilidade de que se entenda a inovação como uma capacidade humana específica. Com efeito, nada impede que a inovação seja assim considerada, como consistindo numa capacidade educacional específica a ser devidamente fomentada pelo Estado mediante as políticas de CTËI. Mas esta característica comum não garante a convergência entre os interesses públicos em saúde e os objetivos das empresas; por exemplo, na área da assistência farmacêutica. Primariamente, o enfoque da inovação está voltado para salvar as economias nacionais e não para salvar vidas com base numa preocupação de equidade, preocupação que poderia garantir o acesso universal aos bens produzidos por inovação. Quanto a este ponto, tem muita relevância o pensamento de Amartya Sen, sempre centrado nas capacidades humanas e nos objetivos da equidade (e não nos indicadores econômicos), demandando que todos possam democraticamente participar do debate público que precisa ocorrer em torno da pergunta: "queremos o desenvolvimento de quê, para quê"?

\section{Referências}

AGHION, P.; ROULET, A. Repenser l'État: Pour une Social-Démocratie de L'Invention. Paris: Seuil, 2011.

ARBIX, G. Caminhos Cruzados, Rumo a uma Estratégia de Desenvolvimento Baseada na Inovação. Novos Estudos CEBRAP, São Paulo, v. 87, p. 13-33, jul. 2010.

ARRIGHI, G. Adam Smith in Beijing: Lineages of the Twenty Century. London: New York: Verso, 2007.

BERLINGUER, G. Medicina e Política. São Paulo: HUCITEC, 1978.

BIELSCHOWSKY, R. Sesenta Años de La Cepal: Estructuralismo Y Neoestructuralismo. Revista de La CEPAL, Santiago de Chile, v. 97, p. 173-194, abr. 2009.

DREZE, J.; SEN, A. Putting Growth in Its Place: It has to be but a means to development, not an end in itself. 2011. Disponível em: < http://www.outlookindia.com/article.aspx?278843>. Acesso em: 26 jan. 2012.

FURTADO, C. El Nuevo Capitalismo. Revista de la Cepal, Santiago de Chile, p.17-20, out. 1998. Número Extraordinário.

GADELHA, C. A. G.; QUENTAL, C.; FIALHO, B. C. Saúde e Inovação: Uma Abordagem Sistêmica das Indústrias da Saúde. Cad. Saúde Pública, Rio de Janeiro, v. 19, n. 1, p. 47-59, jan./fev. 2003.

GADELHA, C. A. G. Desenvolvimento, Complexo Industrial da Saúde e Política Industrial. Rev. Saúde Pública, São Paulo, v. 40, p. 11-23, 2006. N Esp.

GADELHA, C. A. G.; COSTA, L. Integração de fronteiras: a saúde no contexto de uma política nacional de desenvolvimento. Cad. Saúde Pública, Rio de Janeiro, 23 Sup 2:S214-S226, 2007.

JESSOP, B. The Future of the Capitalist State. Cambridge: Polity, 2002. 
NUSSBAUM, M. Creating Capabilities: The Human Development Approach. London: Harvard University Press, 2011.

PÉREZ, C. Dinamismo Tecnológico e Inclusión Social en América Latina: Una Estrategia de Desarrollo Productivo Basada en los Recursos Naturales. Revista de la Cepal, Santiago de Chile, v. 100, p. 123-145, abr. 2010.

PORTO, M. F.; MILANEZ, B. Eixos de Desenvolvimento Econômico e Geração de Conflitos Socioambientais no Brasil: Desafios para a Sustentabilidade e a Justiça Ambiental. Ciência $\mathcal{E}$ Saúde Coletiva, Rio de Janeiro, v. 14, n. 6, p. 1983-1994, dez. 2009.

PRADO JUNIOR, C. História e Desenvolvimento: A Contribuição da Historiografia para a Teoria e Prática do Desenvolvimento. São Paulo: Brasiliense, 1999.

PRIDEMORE, W. A. Vodka and Violence: Alcohol Consumption and Homicide Rates in Russia. American Journal of Public Health, v. 92, n. 12, p. 1921-30, Dec. 2002.

SEN, A. Why Health Equity. In: ANAND, S.; PETER, F.; SEN, A. Public Health, Ethics, and Equity. New York: Oxford University Press, 2004.

. Development as Freedom. New York: Anchor Books, 2000.

. Inequality Reexamined. London: Harvard University Press, 1992.

. Choice, Welfare and Measurement. London: Harvard University Press, 1982.

STIGLITZ, J. Globalização: como dar certo. São Paulo: Cia das Letras, 2007.

VIANA, A. L. D.; ELIAS, P. E. M. Saúde e Desenvolvimento. Ciência \& Saúde Coletiva, Rio de Janeiro, v. 12, p. 1765-1777, 2007. Suplemento.

WALLERSTEIN, I. World-System Analysis: An Introduction. Durham: Duke University, 2004.

WHO. Global Health Risks: mortality and burden of disease attributable to selected major risks. Geneva: WHO, 2009.

. The Ottawa Charter for Health Promotion First International Conference on Health

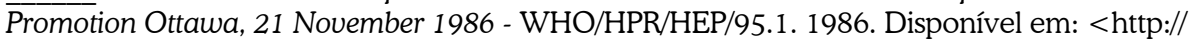
www.who.int/hpr/NPH/docs/ottawa_charter_hp.pdf>. Acesso em: 26 jan. 2012.

Recebido em: 05/03/2012.

Aceito em: 17/05/2012. 